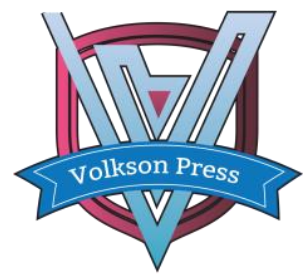

Contents List available at VOLKSON PRESS

Economics \& Management Innovations(EMI)

DOI : http://doi.org/10.26480/icemi.01.2017.168.170

\title{
Research on the Framework of China 's Energy Conservation and Emission Reduction Auditing Evaluation Index System-—Based on PSR Model
}

\author{
Zhang Lu \\ School of Economics and Management Nanjing University of Science and Technology Nanjing, PR China \\ 954229963@qq.com
}

This is an open access article distributed under the Creative Commons Attribution License, which permits unrestricted use, distribution, and reproduction in any medium, provided the original work is properly cited.

\section{ARTICLE DETAILS}

\section{Article History:}

Received 02 october 2017 Accepted 06 october 2017 Available online 11 october 2017

Keywords:

Energy conservation and emission reduction auditing, PSR model, evaluation index system.

\section{ABSTRACT}

With the arrival of the "13th Five-Year Plan" period, China is entering the period of environmental resource constraints. The energy conservation and emission reduction policy, which is a key breakthrough in accelerating the construction of ecological civilization, will play a more important role in building a resource-saving and environmentfriendly society. Besides, the energy conservation and emission reduction auditing has become the focus of current auditing work. So, to further explore the necessity of the implementation of relevant work, an evaluation index system of energy conservation and emission reduction auditing has been built based on PSR model. And this will provide new ideas for the implementation and development of energy conservation and emission reduction auditing.

\section{Introduction}

In the context of China's comprehensively deepening reform and transformation of the pattern of economic development, environmental auditing plays an increasingly important role. At the same time, the energy conservation and emission reduction auditing has also been particularly concerned about. The construction of ecological civilization is an important component of the implementation of China's "five in one" strategic layout, and the energy conservation and emission reduction auditing is also a necessary part of the ecological civilization construction.

As we know, China's energy conservation and emission reduction work has achieved remarkable results in the "12th Five-Year Plan" period, of which the energy consumption per unit of GDP decreased by $18.4 \%$, and the total emissions of major pollutants were reduced by more than $10 \%$, exceeding the scheduled target. Along with the arrival of the "13th FiveYear Plan" era, there are new requirements of the energy conservation and emission reduction work. For example, by 2020, the total energy consumption per 10,000 RMB of GDP should be 15\% lower than that in 2015 , and the total amount of main pollutants (ammonia nitrogen, oxygen, sulfur dioxide and nitrogen oxides) should also drop by more than $10 \%$ compared with 2015 .

Therefore, China's energy conservation and emission reduction auditing evaluation index system still has much room for improvement. First, it can standardize the work of auditors, so that they can make a systematic and objective evaluation of relevant work. Second, the problems of high energy consumption, high pollution and poor supervision are still serious in China, a good indicator system enables relevant work to be more effectively implemented and supervised. Finally, it is conducive to improving China's environmental auditing system and enhancing the practicability of energy conservation and emission reduction auditing work.

\section{Literature Review}

\subsection{Overseas Research Status}

At present, the internationally recognized environmental performance evaluation criteria include: The Environmental Performance Report released by the CICA (Canadian Institute of Chartered Accountants), the IS014031 Environmental Performance Evaluation Standard published by ISO (International Organization for Standardization) and The WBCSD (World Business Council for Sustainable Development) Environmental
Performance Evaluation Standard which regards the ecological benefit as the core indicator.

Wilson and Thompson (1994) believe that information gathered from the process of environmental auditing and evaluations can provide a basis for national or regional environmental reports. Hepler and Neumann (2003) compare three different ways of environmental auditing, and then provide specific suggestions to improve its quality. Feichtinger et al. (2003) argue that environmental policy based on learning and technology is the basic means of energy conservation and emission reduction.

Stanley (2009) establishes a carbon dioxide emission auditing method based on Kaya model. Liu et al (2014) believe that the government can optimize the resources and environmental auditing from the reform of audit evaluation mechanism.

\subsection{Domestic Research Status}

China's research on environmental auditing of energy conservation and emission reduction started in the 1990s. China promulgated some environmental auditing evaluation index systems, such as the Central Government Investment Project Budget Performance Evaluation Work Guidance and so on.

Dong Li (2009) believes that the energy conservation and emission reduction auditing is mainly based on government and civil audit, supplemented by internal audit of enterprises. Gao Zhiyuan (2009) sets up the energy conservation and emission reduction auditing model according to China's practical conditions.

Liu Xin (2014) constructs the basic evaluation index of energy conservation and emission reduction auditing for industrial enterprises Wang Ting (2015) uses expert scoring method and analytic hierarchy process (AHP) to assign the weights to the evaluation indexes of the government auditing on energy conservation and emission reduction. Xu Xiaoling (2016) uses AHP and Matlab to assign the weights to the evaluation indexes of carbon audit evaluation system. Chen Yangyang, Wang Zongjun (2016) use AHP to construct the basic evaluation index system of low carbon auditing. Li Haiyan (2017) combines DSR model and AHP to build a set of low carbon auditing evaluation index system for power enterprises.

\subsection{Summary}


The foreign research of energy conservation and emission reduction auditing is mainly included in environmental auditing. The relevant research is earlier than that of China, and the content is more abundant. However, China's energy conservation and emission reduction auditing evaluation index framework is not always standardized, or to some extent divorced from China's actual situation.

Therefore, this paper hopes to combine current situation in China, and attempts to design a relatively standardized evaluation index system based on PSR model, so as to provide a new direction for China's energy conservation and emission reduction auditing.

3. Energy Conservation and Emission Reduction Auditing Evaluation Index System -- Based on PSR Model

\subsection{PSR Model}

Energy conservation and emission reduction auditing is an important component of environmental auditing in China. It is a special auditing about energy, environment conditions/quality and so on. The relevant departments need to audit the legality, rationality of the special funds used by government or enterprises on the basis of regulatory and policy requirements. Furthermore, energy conservation and emission reduction auditing evaluation is a comprehensive evaluation process from the perspective of efficiency and effectiveness. Through the exploration of many researchers, the evaluation system in China is constantly innovative and improved.

PSR model, that means Pressure-State-Response model. It was originally developed by Tony Friend and David J. Rapport from Canada, and then improved by OECD and UNEP. It is now widely used in environmental quality, especially in ecosystem health assessment. The basic logic of the model is "pressure-effect-response"(see Figure 1), which can reflect the interaction between human and environment. The whole process goes back and forth and never stops.

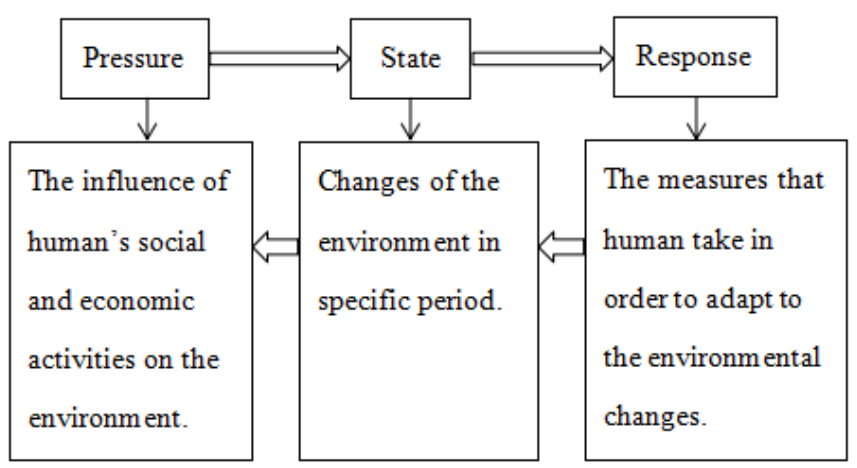

Figure 1 Basic Logic of PSR Model

\subsection{Feasibility Analysis}

PSR model is a reflection of the causal relationship of an issue, so it is highly practical, which is recognized by many governments.

First, the logic of this model is clear. It can effectively identify the pressure that human activities bring on the nature, including the low utilization of resources and environmental pollution; then the pressure will make the system state changes, such as air pollution, waste of resources and so on; finally the relevant departments take measures to weaken these changes, which mean response. The whole process is complete, the pressure leads to changes in state, the changes make the response, and in the end it will help the whole environment system to be healthier.

Second, this model is flexible and comprehensive. The energy conservation and emission reduction auditing is a dynamic process, so the short-term evaluation indexes cannot reflect the actual effect of the work. At this time, PSR model can fully present the whole process of energy conservation and emission reduction, and the whole cycle can help to further improve the environmental system.

Therefore, this paper selects PSR model to construct the basic evaluation index system of energy conservation and emission reduction auditing, which has higher feasibility.

\subsection{Basic Principles}

According to the characteristics of PSR model and the energy conservation and emission reduction auditing work, the following principles should be observed when designing indexes:

(1) Comprehensiveness and representativeness. The indicators should include efficiency, effectiveness and other aspects, so as to provide sufficient information for energy conservation and emission reduction auditing. But it is unrealistic to include all the indicators. Therefore, we should select the indicators that can best represent the characteristics of energy conservation and emission reduction work.

(2) Adaptability. The indicators should be applicable to different time, place and so on, and can continue to improve and develop with the change of national policy and technological progress. Besides, the energy conservation and emission reduction work involves a wide range of fields. Therefore, we should combine static indicators and dynamic indicators to better reflect the effectiveness of energy conservation and emission reduction auditing work.

(3) Maneuverability. It requires that the indicators should be obtained after practical investigation or data processing, and should be clear, so as to be understood easily. At the same time, the index selection should take the actual situation of the evaluation entity into account, so the indicators can meet the needs of the entity.

(4) Comparability. It requires each indicator to be independent so as not to overlap with one another. For example, for different projects of the same enterprise or the same project of different enterprises, each index should be easy to compare. In order to compare, the indexes can also be average value, relative value.

\subsection{The Framework of Energy Conservation and Emission Reduction Auditing Evaluation Index System}

Through the analysis above, this paper establishes energy conservation and emission reduction auditing evaluation indicators based on PSR model. This system includes the target layer, criteria layer, element layer and index layer, among them the target layer refers to the overall goal of the whole index system; the criteria layer reflects specific content of the target layer, including pressure, state and response; the element layer is the further embodiment of the criteria layer, including social, economic, environmental and other aspects; the index layer is the refinement of the target layer, and it is the most basic and intuitive index. So this paper has formed a hierarchical and comprehensive evaluation index system framework (see Table 1)

Table 1 the Framework of Energy Conservation and Emission Reduction Auditing Evaluation Index System

\begin{tabular}{|c|c|c|c|}
\hline Target Layer & $\begin{array}{l}\text { Criteria } \\
\text { Layer }\end{array}$ & Element Layer & Index Layer \\
\hline \multirow{7}{*}{$\begin{array}{l}\text { Table } 1 . \\
\text { Con } \\
\text { energy } \\
\text { conservation }\end{array}$} & \multirow{4}{*}{ pressure } & \multirow{2}{*}{ energy consumption } & $\begin{array}{l}\text { energy consumption of } \\
\text { unit output value }\end{array}$ \\
\hline & & & $\begin{array}{l}\text { recycling utilization of } \\
\text { energy and resource }\end{array}$ \\
\hline & & \multirow[t]{2}{*}{ pollutant emission } & $\begin{array}{l}\text { waste } \\
\text { water/gas/solid/dust } \\
\text { emission of unit output } \\
\text { value }\end{array}$ \\
\hline & & & $\begin{array}{l}\text { recycling utilization of } \\
\text { waste }\end{array}$ \\
\hline & \multirow{8}{*}{ state } & \multirow[b]{2}{*}{ social } & $\begin{array}{ll}\text { satisfaction of } & \text { the } \\
\text { residents around } & \text { the } \\
\text { auditing object } & \end{array}$ \\
\hline & & & $\begin{array}{lr}\text { size of the } & \text { energy } \\
\text { conservation } & \text { and } \\
\text { emission } & \text { reduction } \\
\text { project } & \\
\end{array}$ \\
\hline & & & $\begin{array}{l}\text { investment payback } \\
\text { period }\end{array}$ \\
\hline and & & & \\
\hline emission & & economic & $\begin{array}{l}\text { the change rate of energy } \\
\text { consumption per unit } \\
\text { output value }\end{array}$ \\
\hline $\begin{array}{l}\text { reduction } \\
\text { auditing }\end{array}$ & & & $\begin{array}{l}\text { the change rate of waste } \\
\text { emission per unit output } \\
\text { value }\end{array}$ \\
\hline evaluation & & & $\begin{array}{l}\text { effective utilization rate of } \\
\text { energy }\end{array}$ \\
\hline index & & environmental & $\begin{array}{l}\text { the compliance rate of } \\
\text { waste emission }\end{array}$ \\
\hline system & response & laws/ regulations & 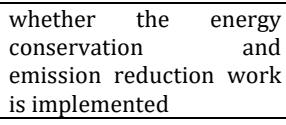 \\
\hline & & & the implementation rate \\
\hline
\end{tabular}




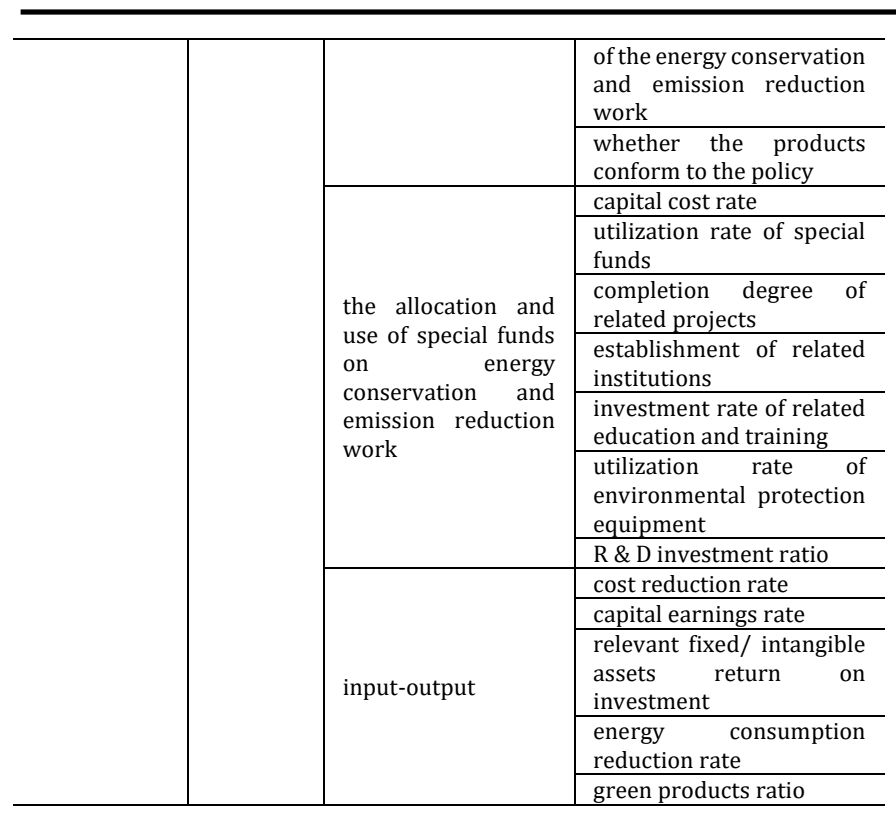

\section{Conclusions}

This paper summarizes the research on evaluation index system of energy conservation and emission reduction auditing at home and abroad, and finds that there is still much room for improvement in this field. Therefore, this paper attempts to build a new framework for the basic evaluation index based on PSR model, hoping to help improve the energy conservation and emission reduction work in China.

On the one hand, we should try to establish a risk oriented audit model of energy conservation and emission reduction, then determine the key auditing projects according to the risk and use the evaluation index flexibly, so as to improve the efficiency and quality of auditing work. On the other hand, this paper only constructs the basic framework of the evaluation index of energy conservation and emission reduction auditing, but the weight of each index needs to be further studied.

\section{References}

[1] Thompson D, Wilson M J. Environmental auditing: Theory and applications[]]. Environmental Management, 1994, 18(4):605-615.
[2] Hepler J A, Neumann C. Enhancing compliance at Department of Defense facilities: comparison of three environmental audit tools[J]. Journal of Environmental Health, 2003, 65(8):17.

[3] Feichtinger G, Hartl R F, Kort P M, et al. Environmental Policy, the Porter Hypothesis and the Composition of Capital: Effects of Learning and Technological Progress[J]. Social Science Electronic Publishing, 2003, 50(2):434-446. .

[4] Stanley C T - Application of Carbon Dioxide Emission Audit to the Planning of Low Carbon Cities[J] - Modern urban research , 2009 , $11: 005$.

[5] Liu C, Zhang H, Huang W. External Environment of Resources and Environment Audit:Structure,Impact and Optimization[J]. Auditing Research, 2014.

[6] Dong Li. Enterprise energy saving and emission reduction audit, [J]. Ecological Economy (Academic Edition), 2009, 02:282 284.

[7] Gao Zhiyuan. Energy conservation and emission reduction environmental auditing research [J]. Friends of Accounting (MidYear), 2009, 04: 58-59.

[8] Liu Xin. Research on the evaluation index of environmental performance audit of industrial enterprises energy saving and emission reduction from the perspective of recycling economy [D]. Ocean University of China, 2014.

[9] Wang Ting. Research on government audit evaluation index system of energy saving and emission reduction [D]. Xi'an University of Petroleum, 2015.

[10] Xu Xiaoling. Basic conception of carbon audit evaluation system [D] Shanxi University of Finance and Economics, 2016.

[11] Chen Yangyang, Wang Zongjun. Preliminary study on evaluation index system of low carbon audit based on analytic hierarchy process [J]. Auditing Research, 2016, (06): 64-71.

[12] Li Haiyan. Construction of low carbon audit evaluation index system for power enterprises based on DSR-AHP [J]. Finance Monthly, 2017, 